\title{
Effects of $\Delta$-9-tetrahydrocannabinol on appetitive- and aggressive-rewarded maze performance in the rat
}

\author{
M. MARLYNE KILBEY and J. WILL MOORE, JR. \\ University of Houston, 3801 Cullen Boulevard, Houston, Texas 77007 \\ and \\ ROBERT T. HARRIS \\ Baylor College of Medicine. 1200 Moursund, Houston, Texas 77025
}

\begin{abstract}
Forty-two rats were trained in a T-maze with the opportunity to obtain food (21 rats) or attack a frog (21 rats) as a reward for choosing the side designated correct. Following training, three dosage levels of $\Delta$-9-tetrahydrocannabinol were administered. Differential effects of drug administration on behavior were found to be a function of the type of reward employed. indicating that $\Delta$-9-tetrahydrocannabinol had a more profound inhibitory effect on aggression than on appetite.
\end{abstract}

A dose-related inhibition of attack behavior in mice following administration of $\Delta$-9-tetrahydrocannabinol (THC) has been shown (Kilbey, Fritchie, McLendon, \& Johnson, 1972). Work by Kilbey, Moore, and Hall ${ }^{1}$ and that of McDonough, Manning, and Elsmore (1972) in the rat has shown $\mathrm{TCH}$ inhibition of predatory aggression to be dose-related and to exist at dose levels that have no effect on motor behavior. The results of these investigations suggest, therefore, that aggressive behaviors may be especially susceptible to disruption by THC. Since THC has been shown to possess an anorexic effect (Manning, McDonough, Elsmore, Saller, \& Sodetz, 1971), however, it is possible that the inhibition of aggression previously reported results from this property of the drug.

We have now investigated the effect of various doses of THC on maze performance in rats whose correct choice was rewarded by food or the opportunity to attack a frog. This allowed a direct comparison of possible THC effects on discrimination of the correct side and on running speed, a measure of motor function, under two reward conditions, as well as a comparison of the latency of the appetitive or aggressive response.

\section{METHOD}

Forty-two male Long-Evans rats were pretrained, then trained to a position habit in a $\mathrm{T}$-maze. Pretraining consisted of three phases. In Phase 1, all rats were given three trials daily for 9 days, during which a 2- to 3 -in. frog (Rana pipiens, northern) was dropped into the home cage and the rat was allowed $3 \mathrm{~min}$ to make an attack of 10 -sec duration. At the completion of this phase, the mean attack time for the final day was computed, and the rats were ranked on this measure. The ranked animals were then assigned in a counterbalanced manner to a food- or frog-rewarded group. Phase 2 was a single day on which the rats were given $3 \mathrm{~min}$ to explore the T-maze. Phase 3 consisted of 9 days during which the rats were placed in the goalbox for four trials daily, on alternate sides, and allowed $3 \mathrm{~min}$ per trial to complete a $10-\mathrm{sec}$ attack or appetitive response, as required by their group assignment. Following this, maze training was initiated. Electronic equipment recorded the time required to run the maze and the latency of the rats' appetitive or aggressive responses. Maze specifications are available from the senior author. Six free-choice, 6-min trials were given daily. The side designated correct was counterbalanced. Selection of the correct side was rewarded with a $100-\mathrm{sec}$ interval. during which the rat could make a 10 -sec appetitive or aggressive response. The appetitive reward was a protein-powder. liquid-ritamin. and water mixture, prepared as follows: $24 \mathrm{mg}$ beef gland protein (Nutritional Laboratories, El Monte, California). $36 \mathrm{ml}$ Vi-Daylin (Ross Laboratories, Columbus. Ohio). and $80 \mathrm{ml}$ water. The aggressive reward was the opportunity to atrack a frog. Selection of the incorrect side resulted in goalbox confinement for 30 sec. During training, both goalboxes were baited to prevent odor differences. The baited area was separated from the goalbox by a door, which was raised to activate the time for the latency measure on correct trials. On incorrect trials, the door remained closed. The $30-\mathrm{sec}$ interval was timed with a stopwatch. Rats were trained to a criterion of at least five correct choices in the six daily trials for 3 consecutive days. As criterion was attained. each rat was given a single tail-vein injection of THC in a polyvinylpyrrolidone K-30 vehicle (Fenimore \& Loy, 1971) at one of the following dose levels: $0.0,1.0$. or $2.0 \mathrm{mg} / \mathrm{kg} .15 \mathrm{~min}$ prior to maze performance. Throughout the experiment, rats were fed water ad lib and standard food pellets to maintain $80{ }^{\prime}$, normal body weight, and they were housed in individual cages under a 12-h light-dark cycle.

\section{RESULTS AND DISCUSSION}

Data were analyzed using the $F$ test for group comparisons and the Newman-Keuls test for individual comparisons (Winer, 1971). Analyses of the number of days of training required for the food- and frog-rewarded groups to reach the first day of criterion performance showed that the aggression-rewarded group required significantly more training $[\mathrm{F}(1,40)=11.86, \mathrm{p} \leqslant .01]$. The $\overline{\mathrm{X}}$ for the appetitive group was $3.09, \mathrm{SD}=2.93$ days, and for the aggression group, $9.85, \mathrm{SD}=8.50$ days. Similar differences in the effectiveness of aggression and food reinforcement for mice in the T-maze paradigm have been reported (Tellegen \& Horn, 1972).

THC disrupted discrimination of the correct side differentially as a function of reward, and the degree of disruption increased with increasing dose level. Since the administration of the PVP vehicle decreased the number of correct choices for the frog-rewarded group $[F(1,12)$ $=13.00, p \leqslant .01]$, the data were analyzed separately for the two reward conditions to determine the effect of 
Table 1

Mean and Standard Deviation for Number of Correct Choices for Appetitive- and Aggressive-Rewarded Rats Under Three Dose Levels of THC

\begin{tabular}{|c|c|c|c|c|c|c|}
\hline \multirow[b]{3}{*}{ Reward } & \multicolumn{6}{|c|}{$\mathrm{THC} \mathrm{mg} / \mathrm{kg}$} \\
\hline & \multicolumn{2}{|c|}{0.0} & \multicolumn{2}{|c|}{1.0} & \multicolumn{2}{|c|}{2.0} \\
\hline & Mean & SD & Mean & SD & Mean & SD \\
\hline Appetitive & 5.85 & 0.37 & 5.00 & 1.52 & 3.14 & 2.03 \\
\hline Aggressive & 4.43 & 0.97 & 3.00 & 1.15 & 0.71 & 0.95 \\
\hline
\end{tabular}

THC administration on discrimination of the correct side. Analysis of the number of correct choices for the food-rewarded groups yielded an $\mathrm{F}(2,18)=6.12$, $\mathrm{p} \leqslant .01$. Individual comparisons indicated that only the $2.0-\mathrm{mg} / \mathrm{kg}$ dose impaired discrimination $(\mathrm{p} \leqslant .05)$. Analyses of these data for the frog-rewarded group yielded an $F(2,18)=23.09, p \leqslant .01$. The individual comparisons indicated that both the $1.0-$ and $2.0-\mathrm{mg} / \mathrm{kg}$ THC levels impaired performance $(p \leqslant .05)$. These data are presented in Table 1.

Mean running time for correct trials was significantly greater for the frog-rewarded group $[F(1,31)=89.35$, $\mathrm{p} \leqslant .01]$ and increased as a function of THC level $[F(2,31)=184.08, p \leqslant .01]$. The interaction factor was significant also $[\mathrm{F}(2,31)=7.20, \mathrm{p} \leqslant .01]$. Individual comparisons showed no significant differences among the food-rewarded groups as a function of dose level, while, within the frog-rewarded group, both the 1.0- and $2.0 \cdot \mathrm{mg} / \mathrm{kg}$ groups ran significantly more slowly $(\mathrm{p} \leqslant .05)$ than the 0.0 group.

Analysis of data for the latency of the appetitive or aggressive goal response also yielded significant main and interaction effects [reward factor, $\mathrm{F}(1,31)=951.52$, $p \leqslant .01 ;$ dose factor, $F(2,31)=101.89, p \leqslant .01$; interaction factor, $F(2,31)=31.88, p \leqslant .01$ ], indicating that the appetitive response was executed faster than the aggressive response and that higher THC levels were associated with increased latencies. Individual comparisons showed no significant changes within the food-rewarded groups as a function of dose level, while, in the frog-rewarded groups, latency increased significantly $(2.0>1.0>0.0 \mathrm{mg} / \mathrm{kg}, \mathrm{p} \leqslant .01)$. Data for run and latency measures are shown in Fig. 1.

The interpretation of these data depend, in part, on the relationship assumed to exist between eating and predation. If hunger is viewed as underlying predation, then these data might be interpreted as indicating (1) that frogs are less appealing appetitively to the rat than the protein-powder/vitamin mixture and (2) that THC disrupts behavior rewarded by a lesser preferred substance more severely than it disrupts behavior rewarded by a more preferred substance. However, since most studies of the possible relationship between eating and predation (e.g., Paul, 1972) have shown that the major variables that control eating do not control predation. it seems more plausible to conceive of eating and predation as responses with different underlying motivational systems. From this point of view, these data indicate that parameters of maze performance as a function of the amount of THC administered vary differentially, depending on the type of reward offered. Only the 2.0 dose affected the accuracy of discrimination performance in the food-rewarded group, while both dosage levels impaired performance in the aggression-rewarded group. The effect of THC on motor behavior also depended on the type of reward: no significant change was observed in the food-rewarded group, while both drug levels increased running time in the frog-rewarded group. This differential effect was seen most clearly in the execution of the goal response. THC had no significant effect on the latency with which the food-rewarded group began eating. The attack latency of the aggression-rewarded group, however, increased significantly at the 1.0 drug level, and no attacks were initiated within the $100 \mathrm{sec}$ allowed by the 2.0 group. Thus, the evidence of this study indicates that THC inhibits the predatory aggression goal response at dose levels which do not inhibit appetitive behavior and support our suggestion (Kilbey, Fritchie, McLendon, \& Johnson, 1972) that THC may possess a specific antiaggression property. The mechanism underlying THC's effect on aggressive behavior is not known, although we have suggested that this effect is mediated by serotonergic (Kilbey, Moore, \& Hall, 1972; Kilbey,

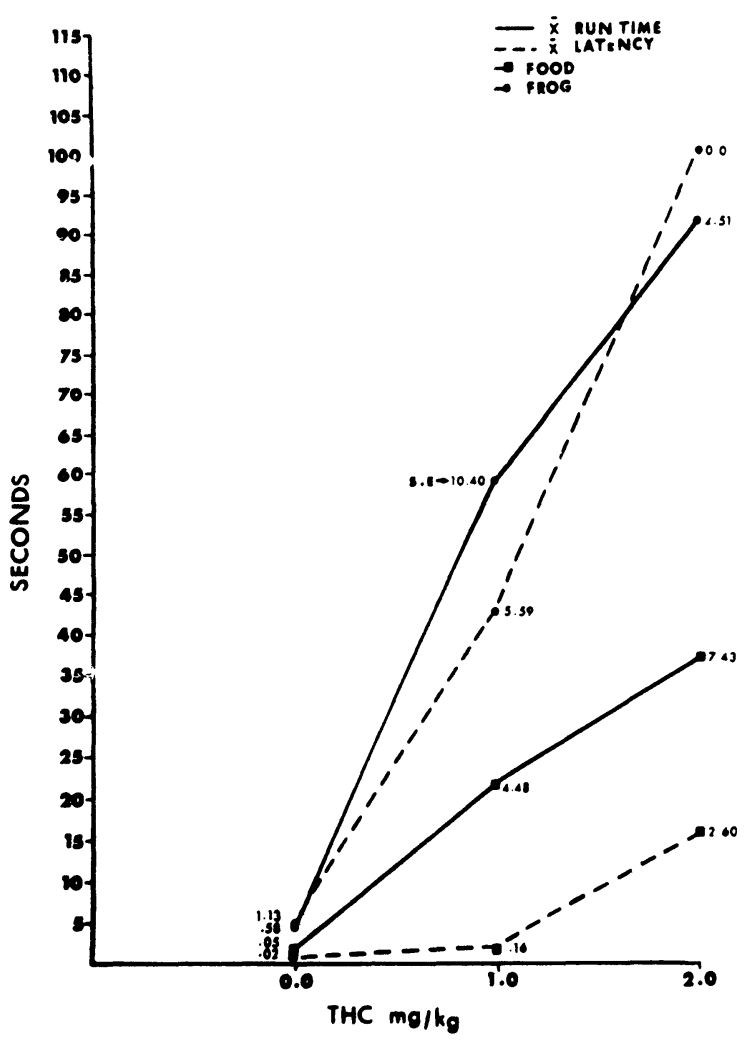

Fig. 1. Mean and standard error (seconds) for run time and latency of the goal response on correct trials for appetitive- and aggressive-rewarded rats under three dose levels of THC. 
Farmer, McLendon, \& Johnson, 1972) and/or anticholinergic (Kilbey, Forbes, \& Olivetti, 1973) properties of the drug.

\section{REFERENCES}

Fenimore. D. C.. \& Loy, P. R. Injectible dispersion of $\Delta^{9}$-tetrahydrocannabinol in saline using polyvinylpyrrolidone. Journal of Pharmacy \& Pharmacology, 1971, 23. 310.

Kilbey, M. M., Fritchie. G. E., McLendon, D., \& Johnson, K. M. A t tack behavior in mice inhibited by $\Delta$-9-tetrahydrocannabinol. Nature, 1972, 238, 463-465.

Kilbey, M. M.. Farmer, R., McLendon, D., \& Johnson, K. M. Time course of $\Delta$-9-tetrahydrocannabinol inhibition of frog killing behavior in the rat. Paper presented to the 19th Annual Convention of the Southwestern Psychoiogical Association. 1972.

Kilbey. M. M., Forbes, W. B., \& Olivetti, C. C. $\Delta$-9-tetrahydrocannabinol: Inhibition of deprivation- and carbachol-induced water consumption in the rat after central and peripheral administration. Behavioral Biology, 1973, in press.

Manning. F. J.. McDonough. J. H.. Jr., Elsmore, T. F., Saller, C.,
\& Sodetz. F. J. Inhibition of normal growth by chronic administration of $\Delta$-9-tetrahydrocannabinol. Science. 1971. 174. 424-426.

McDonough. J. H.. Jr.. Manning. F. J.. \& Elsmore. T. F. Reduction of predatory aggression of rats following administration of delta-9-tetrahydrocannabinol. Life Sciences. 1972. 11. 103-111.

Paul. L. Predatory attack by rats: Its relationship to feeding and ty'pe of pres. Journal of Comparative \& Physiological Psychology. 1972, 78, 69-76.

Tellegen. A., \& Horn. J. M. Primary aggressive motivation in three inbred strains of mice. Journal of Comparative \& Physiological Psychology. 1972. 78, 297-304.

Winer, B. J. Statistical principles in experimental design. (2nd ed.) New York: McGraw-Hill, 1971.

\section{NOTE}

1. Kilbey, M. M., Moore, J. W.. Jr., \& Hall. M. Delta-9-tetrahydrocannabinol induced inhibition of predatory aggression in the rat. In preparation.

(Received for publication November 14. 1972: revision accepted January 26,1973 .) 